Dicle Tıp Dergisi / Dicle Med J (2019) 46 (2) : xxx - xxx

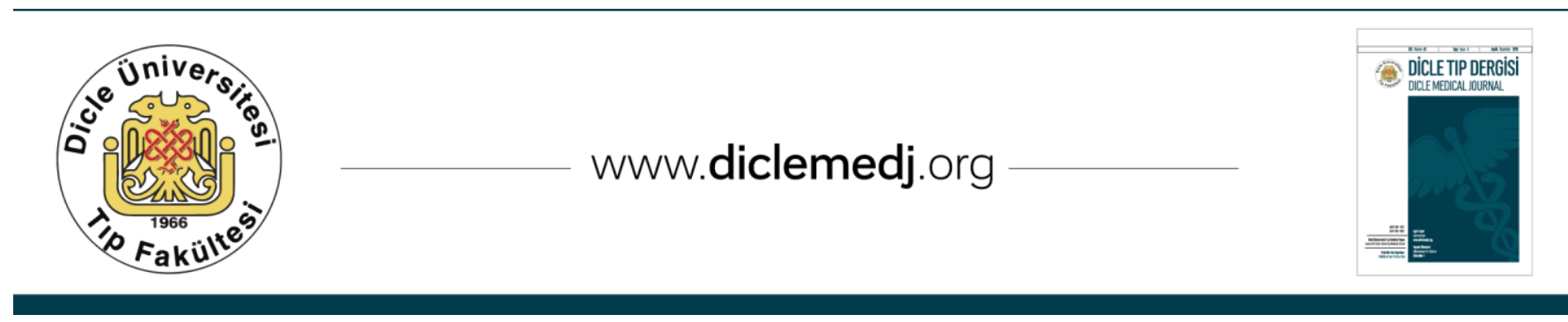

Özgün Araștırma / Original Article

\title{
Helikobakter Pilori Pozitifliği İle Nötrofil Lenfosit Oranı ve Mpv İlişkisi
}

\author{
Murat Akarsuํ, Okan Dikker² \\ 1 Okmeydanı Eğitim ve Araștırma Hastanesi, İç Hastalıkları, İstanbul, Türkiye ORCID: 0000-0002-2675-4252 \\ 2 Okmeydanı Eğitim ve Araştırma Hastanesi, Tıbbi Biyokimya, İstanbul, Türkiye ORCID: 0000-0002-9153-6139
}

Geliş: 05.11.2018; Revizyon: 21.01.2019; Kabul Tarihi: 29.01.2019

Öz

Amaç: Helikobakter pilori pozitifliği, ülkemizde ve dünyada yüksek prevalansa sahip olup kronik gastrit, peptik ülser, mukoza ile ilişkili lenfoid doku lenfoması ve gastrik adenokarsinomla ilişkili bulunmuştur. Helikobakter pilori pozitifliği, yaygın olarak görülmesi ve geniş bir patolojik spektrumu olması nedeniyle halk sağlığı açısından önemlidir. Çalışmamızda nötrofil lenfosit oranı ve ortalama trombosit hacmi ile helikobakter pilori pozitifliği arasındaki ilişkiyi göstermeyi amaçladık.

Yöntemler: Çalışmaya dispeptik şikâyetleri olan hastalardan dışkıda HP direkt antijen testi sonucuna göre HP pozitifliği saptanan 73 olgu ve helikobakter pilori negatif olan 77 olgu çalışmaya alındı. Olgular helikobakter pilori pozitif ve negatif olarak iki gruba ayrıldı. Gruplar arasında laboratuvar parametreleri karşılaştırıldı.

Bulgular: Helikobakter pilori pozitif ve helikobakter pilori negatif hasta grupları arasında yaş ortalaması ve cinsiyet arasında anlamlı farklılık yoktu (sırasıyla $\mathrm{p}=0,26, \mathrm{p}=0.621$ ). Helikobakter pilori enfeksiyonu tespit edilen hastalarda kandaki nötrofil sayısında artma $(p=0,001)$ ve lenfosit sayısında azalma $(p=0,006)$ ile birlikte nötrofil lenfosit oranındaki belirgin artış istatistiksel olarak anlamlıydı $(p=0,001)$. Helikobakter pilori negatif hasta grubuna göre helikobakter pilori pozitif hastalarda C-reaktif protein düzeyleri anlamlı olarak yüksek $(p=0,011)$ ve negatif akut faz reaktanı olarak bilinen albümin anlamlı derecede düşüktü $(\mathrm{p}=0,014)$. Eritrosit sedimantasyon hızı ve ferritin düzeyleri helikobakter pilori pozitif hasta grubunda daha yüksekti ancak iki grup arasında istatistiksel olarak anlamlı fark yoktu. Her iki grup arasında ortalama trombosit hacmi düzeyleri yönünden anlamlı fark bulunamadı $(\mathrm{p}=0,477)$.

Sonuç: Çalışmamızda helikobakter pilori pozitif hastalarda ortalama trombosit hacimlerinde anlamlı bir farklılık görülmezken bu hastalarda artmış nötrofil lenfosit oranı tespit ettik. Dispeptik yakınmalarla gelen hastalarda yüksek nötrofil lenfosit oranı helikobakter pilori pozitifliği için bir belirteç olabilir.

Anahtar Kelimeler: Helikobakter pilori, nötrofil lenfosit oranı, kronik inflamasyon, ortalama eritrosit hacmi.

DOI: 10.5798/dicletip.539924

Yazışma Adresi / Correspondence: Murat Akarsu, 34390 Kaptanpaşa mh. Darülaceze cd. No:27 Okmeydanı E.A.H. 7. Kat, 1. Dahiliye kliniği Şş̧li/ İstanbul, Türkiye e-mail: muratakarsu79@gmail.com 


\title{
The Neutrophil Lymphocyte Rate And Mpv Relationship With Helicobacter Pilori Positivty
}

\begin{abstract}
Objective: Helicobacter pylori positivity has a high prevalence in our country and all over the world, and it has been found that it is associated with chronic gastritis, peptic ulcer, lymphoid tissue lymphoma related to mucosa and gastric adenocarcinoma. HP positivity is important for public health due to the fact that it is endemic and has a wide pathological spectrum. In our study, we aimed to show the relationship between neutrophil lymphocyte ratio and mean platelet volume and helicobacter pylori positivity.

Method: According to the results of helicobacter pylori direct antigen test, in the stool samples taken from patients with dyspeptic complaints, 73 cases detected with helicobacter pylori positivity and 77 cases detected with helicobacter pylori negativity were included in the study. The cases were divided into two groups as positive and negative helicobacter pylori. Laboratory parameters were compared between two groups.

Results: There were no significant differences between the helicobacter pylori positive and helicobacter pylori negative patient groups in terms of age and gender $(p=0.26, p=0.621$, respectively). The increase in the number of neutrophils in the blood $(p=0.001)$ and the decrease in the number of lymphocyte $(p=0.006)$ as well as the distinctive increase in neutrophil lymphocyte ratio $(\mathrm{p}=0,001)$ in patients detected with helicobacter pylori infection were statistically significant. As compared with helicobacter pylori negative patient group, C-Reactive Protein levels were significantly higher $(\mathrm{p}=0.011)$ and albumin, known as negative acute phase reactant, was significantly lower ( $p$ $=0.014$ ) in helicobacter pylori positive patient group. Erythrocyte sedimentation rate and ferritin levels were higher in helicobacter pylori positive patient group but there was no statistically significant difference between two groups. No significant difference was found in terms of mean platelet volume levels $(p=0.477)$ between two groups.

Conclusions: While there was no difference in mean platelet volume values in helicobacter pylori positivity, we found an increased neutrophil lymphocyte ratio in our study. In patients with dyspeptic complaints, a high neutrophil lymphocyte ratio may be an indicator for helicobacter pylori positivity.
\end{abstract}

Keywords: Helicobacter pylori, neutrophil lymphocyte ratio, chronic inflammation, mean corpuscular volüme.

\section{GİRIŞ}

Helikobakter pilori (HP) pozitifliği, batı toplumlarında yaklaşık olarak \% 50'lik bir prevalansın altında iken bu oran gelişmekte olan ülkelerde \% 80'e çıkabilmektedir ${ }^{1,2}$.

HP daha az asidik ortam olduğu için mide antrumunda düzensiz olarak yerleşmeye meyilli mikroaerofilik gram negatif bir bakteridir. HP pozitifliğinde mide mukozası nötrofiller, makrofajlar ve lenfositlerle infiltredir. İmmün sistem, HP virülans faktörleri nedeniyle HP'yi tamamen temizleyemez. Bu uzun süreli enfeksiyon zemininde kronik inflamasyon, oksidatif stres ve DNA hasarı oluşur $^{3}$. Bunun sonucunda da kronik gastrit, peptik ülser, mide lenfoması ve mide kanseri gelişebilir4.
HP'nin mide karsinomu gelişimi için predispozan bir faktör olduğunun belirlenmesi, günümüzde HP tanısına yönelik testlerin hızla gelişmesine neden olmuştur. HP tanısında kullanılan invazif testler; kültür, histoloji, hızlı üreaz testi ve PCR testleridir. Bu altın standart testlerin genellikle biyopsiye dayalı olmaları kullanımlarını sınırlandırmıștır. Noninvazif testler ise üre nefes testi, HP antijenini dışkı örneklerinde aramaya yönelik ELISA testleri ve immünokart testidir. HP direkt antijen testi (HpSA) endoskopiye ve biyopsiye gereksinim duymaması ve invazif yöntemlere oldukça yakın bir duyarlılık ve özgüllükte olmaları nedeni ile klinik pratikte slklıkla kullanılmaktadır 5 .

HP başta serum interlökin-6 (IL-6) olmak üzere, tümör nekroz faktörü (TNF), IL-1 ve IL-8 gibi proinflamatuar sitokinlerinin üretimini 
uyarır6. HP pozitif olan hastalarda IL-6'nın anlamlı derecede yüksek olduğu gösterilmiștir ${ }^{7}$. Birçok inflamatuvar olayda olduğu gibi HP pozitifliğinde de serumda C-Reaktif Protein (CRP) yüksekliği gösterilmiştir ${ }^{8}$. Bilindiği gibi CRP sentezi, IL-6 tarafından düzenlenir.

Lökositler dolaşımdaki strese fizyolojik yanıt olarak nötrofil sayısında artışa ve lenfosit sayısında azalmaya neden olduğundan, bu iki alt grubun birbirine oranı, enflamasyonun duyarlı bir belirleyici olarak kullanılır. Nötrofil lenfosit oranı (NLR) hemogram parametrelerinden elde edilir ve çeşitli hastalıklarda inflamatuar belirteç olarak kullanılmaktadır ${ }^{9}$. Sepsis hastaları ile yapılan bir çalışmada, NLR'nin yüksekliğe neden olan hastalığın şiddeti ve prognozu ile uyumlu olduğu vurgulanmıştır ${ }^{10}$.

Ortalama trombosit hacmi (MPV), sistemik inflamasyonu gösteren rutin ve kolay elde edilen bir gösterge olan hemogramdan elde edilir. Yüksek MPV değerleri, trombositik olaylara katkıda bulunan daha büyük ve aktif trombositler gösterir ${ }^{11}$. Bazı epidemiyolojik çalışmalar HP ile MPV arasındaki korelasyonu göstermiştir. Yapılan bir çalışmada, ülseratif kolit tanılı hastalarda MPV düzeyleri daha düşük bulunmuştur ${ }^{12}$. Literatürde MPV ve inflamasyon hakkında henüz bir fikir birliği yoktur.

Çalışmamızda NLR ve MPV ile HP pozitifliği arasındaki ilişkiyi göstermeyi amaçladık.

\section{YÖNTEMLER}

Bu çalışma dünya Helsinki Tıp Bildirgesinin son versiyonuna ve uluslararası iyi klinik uygulamalarına uygun olup, Sağlık Bilimleri Üniversitesi Okmeydanı Eğitim ve Araştırma Hastanesi Etik Kurulu'nun 06.03.2018 tarih ve 845 sayll etik kurul onayı ile gerçekleştirilmiştir. Kliniğimize dispeptik yakınmalarla başvurmuş, dışkı örneğinde HP direk antijen testi (HpSA) yapılmış ve çalışmaya dahil edilme kriterlerine uygun olan toplam 150 hastaya ait veriler retrospektif olarak incelendi. Dışkıda direkt HP antijeninin aranması nonivaziv, kolay uygulanan ve hassas bir yöntem olması nedeniyle HpSA çalışmamızda tanı testi olarak kullanıldı. Gastrointestinal kanama, gastrik ve duodenal ülser, portal hipertansiyon, kronik hastalıkları olanlar ve nonsteroidal antienflamatuar, proton pompa inhibitörleri ile sitotoksik ilaç kullanan hastalar çalışmaya dahil edilmedi.

HpSA testi ELISA yöntemiyle ölçüldü. HpSA dışkıda görülmüşse pozitif, görülmediyse negatif olarak değerlendirildi. Hastalar HP pozitif ve HP negatif olmak üzere hastalar iki gruba ayrıldı. Bu hasta gruplarında hemogram parametrelerinden MPV ile NLR, sedimantasyon, CRP, ferritin gibi pozitif akut faz reaktanları ve negatif akut faz reaktanlardan albumine ait verileri karşılaştırıldı. NLR, mutlak nötrofil sayısının mutlak lenfosit sayımı ile bölünmesiyle hesaplandı. Hemogram testleri otomatik tam kan sayımı analizöründe çalışıldı.

İstatistiksel analiz: Windows için SPSS 25.0 sürümü (SPSS, Windows 25.0, Chicago, Illinois, ABD) kullanıldı. Gruplar normal dağılım gösteriyordu, bu nedenle gruplar arasındaki farklar ki-kare ve Student t-testi kullanılarak karşılaştırıldı. Laboratuvar verilerinin birbiri ile korelasyonunu değerlendirmek için pearson korelasyon testi kullanıldı. istatistiksel analizler arasındaki sonuçlar ortalama \pm standart sapma (SD) olarak verildi. $\mathrm{p}<0,05$ değeri istatistiksel olarak anlamlı kabul edildi.

\section{BULGULAR}

Çalışmaya alınan 150 hastanın 73 (\%49)'ü HP pozitif idi. HP pozitif hastaların $(n=73)$ yaş ortalaması 41,1 \pm 14 yıl, 39 (\%53,4) kadın, 34 $(\% 46,6)$ erkektir. HP negatif hastalar tüm vakaların \%51'idir. Çalışmamızdaki HP negatif hastaların yaş ortalaması 43,60 \pm 13 yıl, 38 $(\% 48,4)$ kadın, $39(\% 51,6)$ erkektir. Her iki grupta hastalar arasında yaş ve cinsiyet bakımından istatiksel olarak anlamlı fark 
yoktur (sirasiyla; $p=0,26$ ve $p=0.621$ ). HP enfeksiyonu tespit edilen hastalarda kandaki nötrofil sayısında artma $(p=0,001)$ ve lenfosit sayısında azalma $(\mathrm{p}=0,006)$ ile NLR oranında belirgin artış $(p=0,001)$ istatistiksel olarak anlamlıydı. HP negatif hastalarla karşılaştırıldığında CRP'nin HP pozitif hastalarda anlamlı olarak daha yüksek $(p=0,011)$ idi. ESR ve ferritin HP pozitif hasta grubunda daha yüksekti ancak istatistiksel olarak anlamlı fark yoktu. Negatif akut faz reaktanı olarak bilinen albümin HP pozitif hastalarda istatistiksel olarak anlaml derecede düşüktü $(p=0,014)$. HP pozitif ve HP negatif gruplarda trombosit sayıları ve MPV değerleri arasında istatiksel olarak anlamlı fark yoktu ( $p=0,765$ ve $p=477$ ) [tablo 1].

Tablo 1: HP negatif ve HP pozitif verilerinin karşılaştırılması ve istatistiksel anlamlılık düzeyleri

\begin{tabular}{|llll|}
\hline & HP negatif $(\mathrm{n}=77)$ & HP pozitif $(\mathrm{n}=73)$ & $\mathrm{p}$ \\
\hline Cinsiyet & Kadın:\%49,3(38) & Kadın:\%53,3(39) & 0,621 \\
& Erkek:\%51,7(39) & erkek:\%46,6(34) & \\
Yaş(y1) & $43,6 \pm 13$ & $41,1 \pm 14,4$ & 0,260 \\
Glukoz(mg/dL) & $92,7 \pm 12,7$ & $89,2 \pm 12,3$ & 0,149 \\
Üre(mg/dL) & $25,5 \pm 7,2$ & $24,6 \pm 7,1$ & 0,413 \\
Kreatinin(mg/dL) & $0,68 \pm 0,12$ & $0,65 \pm 0,15$ & 0,124 \\
AST(U/L) & $19,9 \pm 5,9$ & $21,3 \pm 11,5$ & 0,311 \\
ALT(IU/L) & $20,01 \pm 9,9$ & $20,2 \pm 11,8$ & 0,920 \\
Albümin(g/dL) & $4,3 \pm 0,28$ & $4,1 \pm 0,27$ & $\mathbf{0 , 0 1 4}$ \\
Ferritin( $(\mu \mathrm{g} / \mathrm{L})$ & $47,01 \pm 8$ & $57,2 \pm 7,4$ & 0,358 \\
CRP(mg/dL) & $3,33 \pm 2,8$ & $4,94 \pm 2,6$ & $\mathbf{0 , 0 1 1}$ \\
ESR(mm/saat) & $15,9 \pm 10,3$ & $19,5 \pm 12$ & 0,108 \\
WBC $(\mu \mathrm{L})$ & $8,84 \pm 3,3$ & $9,1 \pm 1,4$ & 0,124 \\
PLT(10 $/ \mu \mathrm{L})$ & $262,7 \pm 55,3$ & $260,2 \pm 45,6$ & 0,765 \\
MPV(fL) & $9,8 \pm 1,3$ & $9,6 \pm 1$ & 0,477 \\
NLR & $1,88 \pm 0,6$ & $2,7 \pm 0,6$ & $\mathbf{0 , 0 0 1}$ \\
Nötrofil $\left(10^{3} / \mu \mathrm{L}\right)$ & $4,04 \pm 1,01$ & $5,02 \pm 1,13$ & $\mathbf{0 , 0 0 1}$ \\
Lenfosit $\left(10^{3} / \mu \mathrm{L}\right)$ & $2,40 \pm 0,65$ & $2,07 \pm 0,50$ & $\mathbf{0 , 0 0 6}$ \\
\hline
\end{tabular}

ALT: Alanin aminotransferaz, AST: Aspartat aminotransferaz, CRP: C-reaktif protein, ESR: Eritrosit sedimentasyon hızı, MPV: Ortalama trombosit hacmi, NLR: Nötrofil /lenfosit oranı, PLT: Trombosit sayısı, WBC: Beyaz küre sayısı

Helikobakter pilori antijeni varlı̆̆ı ile albümin arasinda negatif yönde anlamlı korelasyon saptandı. Ayrıca HP antijeni varlığı ile CRP ve NLR arasında pozitif yönde anlamlı korelasyon saptandı [tablo 2].

\section{TARTISSMA}

HP enfeksiyonu, konakçı tarafından kronik inflamatuvar yanita neden olur. Gastrik mukoza hücrelerinin salgıladığı sitokinler patojeni ortadan kaldırmak için etkisiz kalır ve HP virulans faktörlerinin de etkisiyle konakçı için zararlı bir mikroçevreye dönüşür. HP ile enfekte olmuş hastalarda \%15-20 oranında peptik ülser, $\% 2-12$ peptik ülser komplikasyonları ve $\% 0,1$ oranında primer mide MALT lenfoması oluşabilir. HP pozitif hastalar, HP negatif hastalara göre 4 kat daha yüksek kanser riski taşırlar" 
Tablo 2: Helikobakter Pilori Antijeni Varlı̆̆ı ile Diğer Testler Arasındaki Korelasyon

\begin{tabular}{|lll|}
\hline parametre & $\mathbf{r}$ & $\mathbf{p}$ \\
\hline Albümin & $\mathbf{- 0 , 2 4 9}$ & $\mathbf{0 , 0 1 4}$ \\
Ferritin & 0,097 & 0,358 \\
CRP & $\mathbf{0 , 2 0 7}$ & $\mathbf{0 , 0 1 1}$ \\
ESR & 0,132 & 0,108 \\
WBC & 0,126 & 0,124 \\
PLT & 0,025 & 0,765 \\
MPV & $-0,058$ & 0,477 \\
NLR & $\mathbf{0 , 5 5 2}$ & $\mathbf{0 , 0 0 1}$ \\
\end{tabular}

CRP: C-reaktif protein, ESR: Eritrosit sedimentasyon hızl, MPV: Ortalama trombosit hacmi, NLR: Nötrofil /lenfosit oranı, PLT:

Trombosit sayısı, WBC: Beyaz küre sayısı

$\mathrm{Bu}$ çalışmada HP tanısında ELISA yöntemiyle dışkıda bakılan, duyarlılığı ve özgüllüğü yüksek bir test olan HpSA yöntemiyle konmuştur. Noninvaziv ve dışkıda bakılan immunokart testinin duyarlılığı yüksek ancak özgüllüğü HpSA ELISA yöntemine kıyasla çok daha düşüktür 5 .

Yapılan çalışmalarda HP pozitif hastalarda sedimantasyon, fibrinojen ve CRP gibi akut faz reaktanları yüksek bulunmuş ve HP ile sistemik inflamatuvar yanıt arasında sıkı bir ilişki olduğu gösterilmiştir ${ }^{8}$. Yaptığımız çalışmada, incelediğimiz pozitif akut faz reaktanlarının hepsinde de HP pozitif grup lehine artış vardı. Ancak istatistiksel olarak CRP ile HP pozitifliği arasındaki ilişki anlamlı derecedeydi.

Hemogram, hemoglobin ve lökosit gibi değerlerin yanında MPV, mutlak lenfosit ve mutlak nötrofil değerlerini ve NLR oranını da verir. HP enfeksiyonunun değerlendirilmesinde hemogram parametreleri katkıda bulunabilir.

Son yıllarda yapılan epidemiyolojik çalışmalarda MPV düzeyleri kronik inflamasyon ile ilişkilendirilmiştir ${ }^{11,13}$. Yüksek MPV değerleri, trombositik olaylara katkıda bulunan daha büyük ve aktif trombositleri işaret eder. Daha büyük trombositlerin proinflamatuar ve protrombotik olaylara katkıda bulunduğu gösterilmiştir ${ }^{11}$. HP ile MPV ilişkisini araștıran çalışmalar çelişkili sonuçlar içermektedir. Anlamlı fark olduğunu bulan çalışmaların yanında $^{14}$ HP ile MPV ilişkisi olmadığını gösteren çalışmalar mevcuttur ${ }^{15}$.Topal ve ark. yaptığı çalışmada MPV düzeyleri ile HP yoğunluğu ve inflamasyon arasında bir ilişki olmadığını bildirmişlerdir ${ }^{16}$. Yapılan bir çalışmada ılımlı HP pozitifliğinin MPV ile ilişkisi olmadığı sonucuna ulaşılmıştır ${ }^{15}$. Çalışmamızda da MPV ile HP pozitifliği arasında anlamlı ilişki bulamadık. Literatür incelemesi yaptığımızda da MPV ve inflamasyon hakkında net bir fikir birliği yoktur. Belki de düşük dereceli kronik inflamasyon ile seyreden HP pozitifliği MPV değerlerinde yeteri kadar artışa neden olmuyor olabilir. Daha geniş örneklem sayılı çalışmalara ihtiyaç vardır.

NLR, inflamasyon varlığını gösteren bir parametre olarak son yıllarda sıkça kullanılmaktadır. Bir çalışmada HP gastritinin şiddeti ile NLR değerleri arasında bir paralellik tespit edilmiştir ${ }^{17}$. Yapılan bir başka çalışmada ise HP pozitif hastalarda, HP negatif hastalara göre, peptik ülserden bağımsız olarak lökosit, nötrofil ve NLR oranları daha yüksekti18. HP'nin mide mukozasındaki yoğunluğu arttıkça periferik kanda inflamasyona cevaben mutlak lenfosit sayısı artar. Yaptığımız çalışmada literatür verileriyle uyumlu olarak NLR, HP pozitif grupta HP negatif gruba göre anlamlı olarak daha yüksek saptadık.

HP(+)'liğinin gastrik dokuda yaptığı kronik inflamasyon polimorfonükleer lökositlerin artışına neden olarak NLR oranının HP ile enfekte grupta daha yüksek olmasını açıklar. Zayıf pozitif yada ılımlı HP pozitifliğinde NLR ve MPV oranı başka bir çalışma konusu olabilir.

Bilindiği gibi HP, invaziv bir mikroorganizma değildir ve düşük dereceli kronik inflamasyona neden olur. Son ylllarda HP eradikasyonunun gerekli olup olmadığını sorgulanmakta ve HP eradikasyonunun mikrobiataya zarar verdiği 
vurgulanmaktadır ${ }^{19,20} . \quad \mathrm{Bu}$ çalışmalarda probiyotikler HP inflamasyonunu zayıflatmanın bir yolu olarak sunulmuştur. Akut faz reaktanları, MPV değeri ve NLR, HP ilişkili kronik inflamasyonun şiddetini ölçmemize yardımcl olabilir ve klinik pratikte HP eradikasyonun gerekliliği konusunda da bize fikir verebilir.

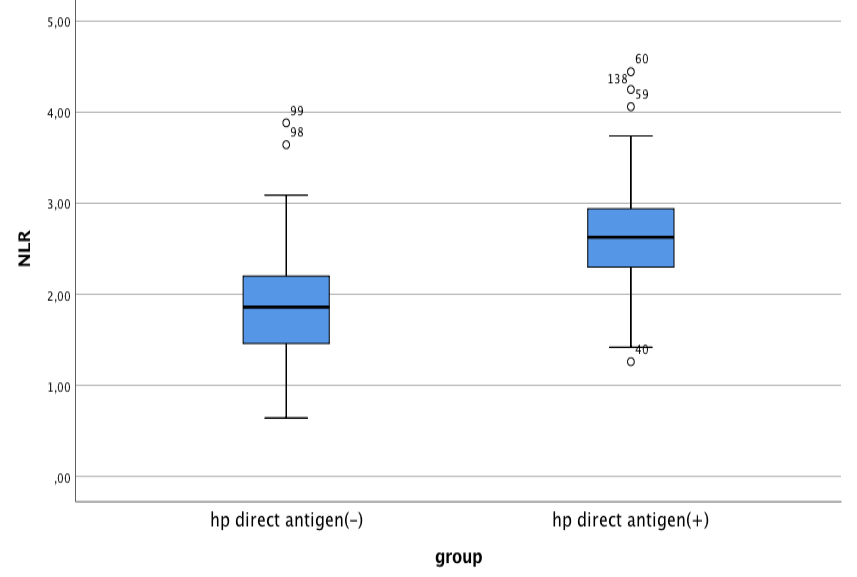

Şekil 1: HP direkt antijen pozitif ve HP direkt antijen negatif gruplarda NLR ilişkisinin box-plot yöntemiyle şematik gösterimi NLR: Nötrofil Lenfosit oran1, HP: Helikobakter pilori

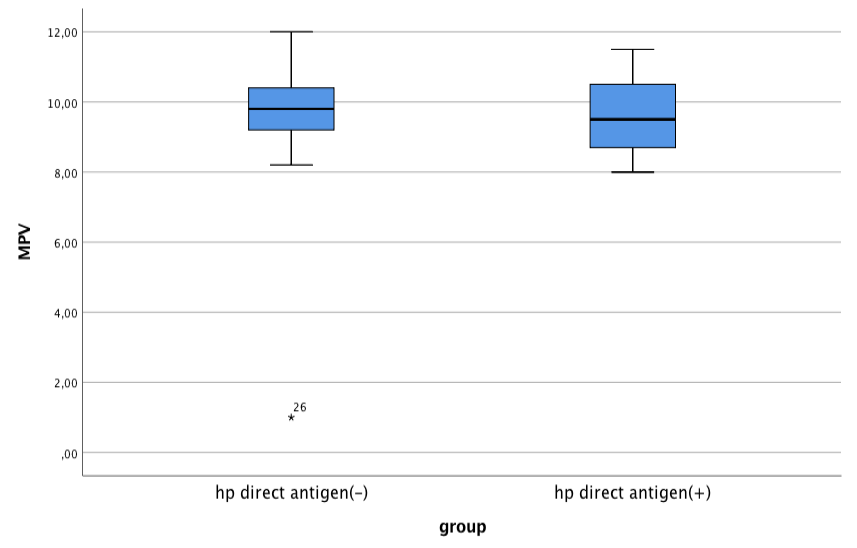

Şekil 2: HP direkt antijen pozitif ve HP direkt antijen negatif gruplarda MPV ilişkisinin box-plot yöntemiyle şematik gösterimi MPV: Ortalama trombosit hacmi, HP: Helikobakter pilori

İnvazif yöntemlere başvurmak yerine hastaların fizik muayene, anamnez, akut faz reaktanları ve hemogram parametreleri değerlendirerek HP pozitifliği öngörülebilir. Gerekli ise HP pozitifliğini doğrulamak için noninvazif HpSA ELİSA testi istenebilir. Böylece hem invazif testlerden hem de gereksiz noninvazif testlerin maliyetinden kaçınılmış olunur. HpSA testinin uygulanamadığı kırsal bölgelerde klinik bulguların uyumlu olması ve başka bir nedene bağlanmayan akut faz reaktanlarının yüksekliği MPV ve NLR HP pozitifliği yönünden alarme edici olabilir.

\section{SONUÇ}

Çalışmamızda HP pozitifliğinde MPV değerlerinde bir farklılık görülmezken artmış NLR oranı tespit ettik. Dispeptik yakınmalarla gelen hastalarda yüksek NLR oranı HP pozitifliği için bir belirteç olabilir.

Çıkar Çatışması Beyanı: Yazarlar çıkar çatışması olmadığını bildirmişlerdir.

Finansal Destek: Bu çalışma her hangi bir fon tarafından desteklenmemiştir.

Declaration of ConflictingInterests: The authors declare that they have no conflict of interest.

Financial Disclosure: No financial support was received.

\section{KAYNAKLAR}

1. Huang Y, Wang QL, Cheng DD, et all. Adhesion and Invasion of Gastric Mucosa Epithelial Cells by Helicobacter pylori. Front Cell Infect Microbiol. 2016; 22; 6: 159.

2. Zhang M, Zhou YZ, Li XY, et all. Seroepidemiology of Helicobacter pylori infection in elderly people in the Beijing region, China. World J Gastroenterol. 2014; 20: 3635-9.

3. Simard J C, Cesaro A, Chapeton-Montes J, et all. S100A8 and S100A9 induce cytokine expression and regulate the NLRP3 inflammasome via ROS-dependent activation of NF- $\kappa$ B1. PloS One, 2013; 19: 8-8.

4. Wang F, Meng W, Wang B, et all. Helicobacter pyloriinduced gastric inflammation and gastric cancer. Cancer Lett. 2014; 345: 196-202.

5. Dalla Nora M, Hörner R, De Carli DM, et all. Is The Immunocromatograpic Fecal antigen Test Effective For Primary Diagnosis of Helicobacter Pylori Infection in Dyspeptic Patients? Arg Gastroenterol. 2016; 53: 224-7. 
6. Yu H, Lee H, Herrmann A, et all. Revisiting STAT3 signalling in cancer: new and unexpected biological functions. Nat Rev Cancer 2014; 14: 736-46.

7. Nakagawa H, Tamura T, Mitsuda Y, et all. Significant association between serum interleukin-6 and Helicobacter pylori antibody levels among $\mathrm{H}$. pyloripositive Japanese adults. Mediators Inflamm. 2013; 2013: 142358-5.

8. Jia Y, Qu B, Wang B, et all. Effects of Active and Latent H. Pylori Infection Coupled With Chronic Alcohol Ingestion on Cytokine Profiles and Markers of Oxidative Balance in Men Seropositive For H. Pylori CagA Ab: An Observational Study. Medicine (Baltimore). 2018; 97: 34.

9. Farah R, Hamza H, Khamisy-Farah R. A link between platelet to lymphocyte ratio and Helicobacter pylori infection. J Clin Lab Anal. 2018; 32: 1.

10. Patel A, Laffan MA, Waheed U, et all. Randomised trials of human albumin for adults with sepsis: Systematic review and meta-analysis with trial sequential analysis of all-cause mortality. BMJ. 2014; 22: 349-4561.

11. Ates I, Bulut M, Ozkayar N, et all. Association between high platelet indices and proteinuria in patients with hypertension. Ann Lab Med. 2015; 35: 630-4.

12. Matowicka J, Karna J. Markers of inflammation, activation of blood platelets and coagulation disorders in inflammatory bowel diseases. Postepy Hig Med Dosw. 2016; 70: 305-12.

13. Shah B, Sha D, Xie D, et all. The relationship between diabetes, metabolic syndrome, and platelet activity as measured by mean platelet volume: the National Health and Nutrition Examination Survey, 1999-2004. Diabetes Care. 2012; 35: 1074-1078.
14. Umit H, Umit EG. Helicobacter pylori and mean platelet volume: a relation way before immune thrombocytopenia? Eur Rev Med Pharmacol Sci. 2015; 19: 2818-23.

15. Güçlü M, Agan F. Association of Severity of Helicobacter pylori Infection with Peripheral Blood Neutrophil to Lymphocyte Ratio and Mean Platelet Volume. Euroasian J Hepatogastroenterol. 2017; 7: 1116.

16. Topal F, Karaman K, Akbulut S, et all. The relationship between mean platelet volume levels and the inflammation in Helicobacter pylori gastritis. J Natl Med Assoc. 2010; 102: 726-30.

17. Farah R, Khamisy-Farah R. Association of neutrophil to lymphocyte ratio with presence and severity of gastritis due to Helicobacter pylori infection. J Clin Lab Anal. 2014; 28: 219-23.

18. Jafarzadeh A, Akbarpoor V, Nabizadeh M, et all. Total leukocyte counts and neutrophil-lymphocyte count ratios among Helicobacter pylori-infected patients with peptic ulcers: independent of bacterial CagA status. Southeast Asian J Trop Med Public Health. 2013; 44: 82-88.

19. Chen L, Xu W, Lee A, et all. The impact of Helicobacter pylori infection, eradication therapy and probiotic supplementation on gut microenvironment homeostasis: An open-label, randomized clinical trial. EBioMedicine 2018; 35: 87-96.

20. Westerik N, Reid G, Sybesma W, et all. The Probiotic Lactobacillus rhamnosus for Alleviation of Helicobacter pylori-Associated Gastric Pathology in East Africa. Front Microbiol. 2018; 14: 9-1873. 